\title{
Which patient will feel down, which will be happy? The need to study the genetic disposition of emotional states
}

\author{
Mirjam A. G. Sprangers $\cdot$ Meike Bartels $\cdot$ Ruut Veenhoven $\cdot$ Frank Baas $\cdot$ \\ Nicholas G. Martin • Miriam Mosing • Benjamin Movsas • Mary E. Ropka • \\ Gen Shinozaki • Dick Swaab · The GENEQOL Consortium
}

Accepted: 1 April 2010/Published online: 24 April 2010

(C) The Author(s) 2010. This article is published with open access at Springerlink.com

\begin{abstract}
Purpose In quality-of-life (QL) research, the genetic susceptibility of negative and positive emotions is frequently ignored, taken for granted, or treated as noise. The objectives are to describe: (1) the major findings of studies addressing the heritable and environmental causes of variation in negative and positive emotional states and (2) the major biological pathways of and genetic variants involved in these emotional states.

Methods Literature overview.

Results The heritability estimates for anxiety and depression are $30-40 \%$. Related traits as neuroticism and loneliness are also highly heritable. The hypothalamopituitary-adrenal axis is the 'final common pathway' for most depressive symptoms. The many findings of investigated genes are promising but not definitive. Heritability
\end{abstract}

M. A. G. Sprangers ( $\square)$

Department of Medical Psychology/J3-211, Academic Medical

Center, University of Amsterdam, Meibergdreef 15, 1105

AZ Amsterdam, The Netherlands

e-mail: m.a.sprangers@amc.uva.nl

M. Bartels

Department of Biological Psychology, VU University,

Amsterdam, The Netherlands

R. Veenhoven

Faculty of Social Sciences, Erasmus University Rotterdam,

Rotterdam, The Netherlands

F. Baas

Laboratory of Neurogenetics, Academic Medical Center,

University of Amsterdam, Amsterdam, The Netherlands

N. G. Martin · M. Mosing

Queensland Institute of Medical Research, Brisbane, Australia estimates of positive emotional states range between 40 and 50\%. Life satisfaction and mental health share common genetic factors with optimism and self-esteem. The prefrontal cortex is a candidate brain area for positive emotional states. Biological and genetic research into positive emotional states is scarce.

Conclusion Genetically informative studies may provide insights into a wide variety of complex questions that traditional QL studies cannot deliver. This insight in turn will help us to design more effective supportive programs that could moderate the outcomes of genetically based predispositions.

Keywords Review - Positive emotional states . Negative emotional states - Biological pathways . Genes

\author{
B. Movsas \\ Department of Radiation Oncology, Henry Ford Health System, \\ Detroit, MI, USA \\ M. E. Ropka \\ Cancer Prevention and Control Program, Fox Chase Cancer \\ Center, Cheltenham, PA, USA \\ G. Shinozaki \\ Department of Psychiatry and Psychology, Mayo Clinic, \\ Rochester, MN, USA \\ D. Swaab \\ Department Neuropsychiatric Disorders, Netherlands Institute \\ for Neuroscience, An Institute of the Royal Netherlands \\ Academy of Arts and Sciences, Amsterdam, The Netherlands
}




$\begin{array}{ll}\text { Abbreviations } \\ \text { SCN } & \text { Suprachiasmatic nucleus } \\ \text { PVN } & \text { Hypothalamic paraventricular nucleus } \\ \text { AVP } & \text { Vasopressin neurons } \\ \text { CRH } & \text { Corticotropin-releasing hormone } \\ \text { ACTH } & \text { Adrenocorticotropin }\end{array}$

\section{Introduction}

Psychological or mental functioning is one of the key components of quality of life (QL) and encompasses the entire spectrum of psychological well-being: from anxiety and depression on the one hand to happiness and life satisfaction on the other. Since being confronted with a disease is one of the major stressors in life, it is understandable that patient-based QL research has focused primarily on the negative end of this range. Frequently used QL questionnaires, such as the European Organisation for Research and Treatment of Cancer QL questionnaire (EORTC QLQ-C30), exclusively inquire about negative emotions (e.g., being tense, worried, irritable, depressed) [1]. In the area of health psychology, the stress process has also been described predominantly in terms of negative emotions. This focus may have stemmed from the acknowledgment that negative emotions have adaptive value as they mobilize the fight/flight response and focus attention on the problem at hand [2].

However, there is mounting evidence that positive emotions co-occur with negative emotions during intensely stressful periods of life [2,3]. Positive emotions have also been found to have adaptive significance as they may broaden the individual's attentional focus and behavioral repertoire, thereby increasing the person's intellectual, social, and physical resources [4]. There is a growing empirical body of research showing that positive emotions have a salutary impact on health, particularly regarding the immune system response and pain tolerance [5, 6]. In other words, happy people are in general healthier. The World Health Organization has started to emphasize happiness as a component of health [7], and the British Medical Journal has recently published an article on the dynamic spread of happiness along connections in a large social network and the implications for healthcare [8].

The balance between negative and positive emotions may differ within persons over time, e.g. immediately after the diagnosis of a disease, negative emotions will likely prevail. The balance between negative and positive emotions also differs across individuals. We all know persons whose view on life is gloomy and somber irrespective of happy and fortunate circumstances. Conversely, we can all name people who persist in a sunny and cheerful view on life despite setbacks and mayhem. In patient-based QL research, this inborn nature is frequently ignored, taken for granted, or treated as noise. The field of QL research would benefit from taking this genetic component into account. Insight into the genetic and environmental components of patient-reported emotional states will ultimately allow us to explore new pathways for improving patient care. If we can identify patients who have a high risk of experiencing poor psychological functioning, we will be able to better target psychological support and/or pharmacological treatment. In other words, we will be able to direct our limited resources in a timely fashion to those who are most likely to need them.

Research on twins, multi-generational families, and population-based cohorts has provided ample empirical evidence of a genetic predisposition for negative emotional states, such as depression, anxiety, and loneliness. Additionally, an increasing number of studies showed substantial heritability of positive emotional states, such as subjective well-being, happiness, and life satisfaction. The objectives of this paper are first to describe the major findings of the studies addressing the heritable and environmental causes of variation in individual differences in negative and positive emotional states. Second, we will describe the major biological pathways of and genetic variants involved in these emotional states. We will thus describe those biological pathways and genetic variants that affect QL, which is consistent with the adapted theoretical model of Wilson and Cleary [9] as described by Sprangers et al. [10]. Since more biological and genetic research has been conducted in negative than in positive emotional states, the paper will reflect this imbalance.

Negative and positive emotional states are commonly reported in separate papers. We purposefully bring these findings together as helping patients to achieve a high level of well-being requires targeting both negative and positive affect.

\section{Negative emotional states}

\section{Causes of individual differences}

Genetic as well as environmental factors play a role in the etiology of negative emotional states, such as anxiety and depression. The heritability estimates for both anxiety and depression disorders range between 30 and $40 \%$. These percentages most likely represent the lower bound. Actual heritability may be higher when measurement error could be ruled out and depression could be perfectly reliably assessed $[11,12]$. The remaining variance can be attributed to individual-specific environmental influences, as 
indicated by two meta-analyses $[11,12]$. It should be noted that the environmental influence already starts in the womb [13]. According to twin and family studies, anxiety and depression have a common genetic background. They also share a common genetic factor with neuroticism. Thus, it is likely that neuroticism is the personality trait underlying these disorders $[14,15]$. Neuroticism refers to the tendency to experience negative emotions such as fear, sadness, and anger. This trait is also being referred to as negative affectivity or emotionality [16]. The heritability estimates of neuroticism have also been found to range around $30-40 \%$ [17]. Findings in adolescents generally support findings in adults and young children that neuroticism is influenced principally by genetic and unique, non-shared environmental factors [16].

Many patients may also experience the pain of loneliness that a chronic or disabling disease may induce. Loneliness can be described as feelings of social isolation and dissatisfaction with one's social relationships. There is robust evidence that loneliness plays a pivotal role in emotional states, such as mood, anxiety, anger, pessimism, and dysphoria [18]. Loneliness also has a significant genetic component. In a cross-sectional study of adult twins, the heritability estimate for variation in loneliness scores averaged over items and measurement occasions was found to be around 50\% [19]. In a longitudinal analysis of two individual items ("I feel lonely" and "Nobody loves me"), the heritability in young adults (below 35 years) was found to be 77 and $70 \%$ respectively and 41 and 54\% in older adults [18]. This finding of a heritability of around $50 \%$ is replicated in children, using an average score of loneliness over ages 7, 10, and 12 [20]. The longitudinal analyses in this study show, however, that heritability is $58 \%$ at age $7,56 \%$ at age 10 but drops to $26 \%$ at age 12 . A parallel increase in influences of shared family environment is observed, explaining $6 \%$ of the variance at age 7 , $8 \%$ at age 10 , and $35 \%$ at age 12 . The remaining variance is explained by relatively stable influences of non-shared environmental factors. Stability in loneliness is high with correlations over time ranging between 0.51 and 0.69 , indicating that individuals who score high on loneliness at a young age have a substantial chance to stay lonely throughout childhood, whereas gregarious youngsters have a small chance of suddenly becoming lonely.

\section{Biological pathways}

In this section and the next section on genetic variants, we will focus primarily on anxiety and depression, as these negative emotional states elicited a great deal of biological and genetic research. The hypothalamo-pituitary-adrenal (HPA) axis is considered to be the 'final common pathway' for most depressive symptoms [13] and thus may be important for patient-reported distress. Indeed, a large part of the environmental and genetic risk factors for depression appear to correlate with increased HPA-axis activity in adults. Figure 1 illustrates the pathogenesis of depression as formulated by Bao et al. [13]. In depressed patients, stress acting on the HPA axis results in a disproportionately high activity of this system due to a deficient cortisol feedback effect. Such an impaired negative feedback mechanism and overreaction of the HPA-axis to stress may be based on genetic factors and environmental factors, including placental dysfunction, smoking of the pregnant mother, or child abuse. High corticotropin-releasing hormone (CRH) and cortisol levels contribute to symptoms of depression by their central effects. The set point of the HPA-axis is at least partly genetically determined. For example, the heritability estimate of basal cortisol levels was found to be $62 \%$, as indicated by a simultaneous analysis of five comparable twin studies [21].
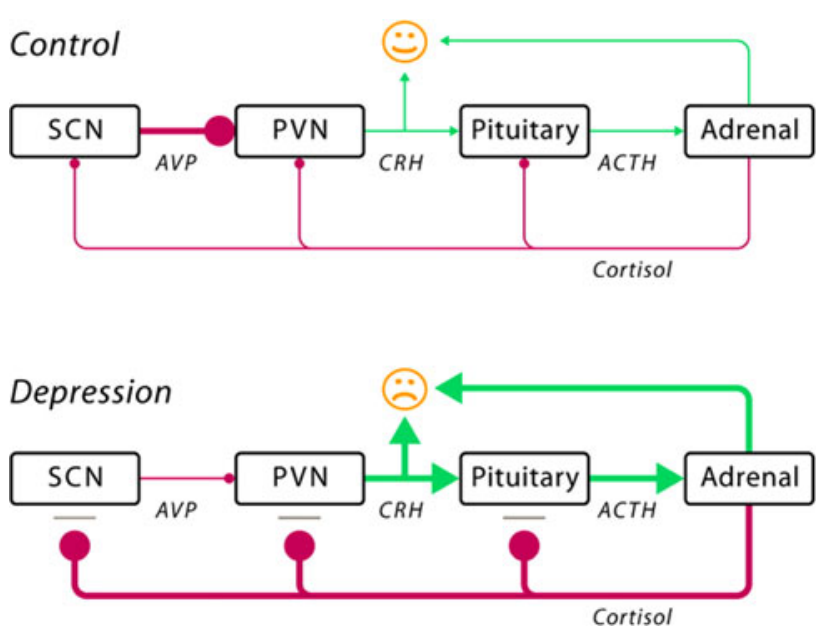

Fig. 1 Schematic illustration of the pathogenesis of depression (reprinted with permission from Bao et al., 2008 [13], p. 541). The schematic figure illustrates the impaired interaction among the decreased activity of vasopressin neurons $(A V P)$ in the suprachiasmatic nucleus $(S C N)$, the increased activity of corticotropin-releasing hormone $(C R H)$ neurons in the paraventricular nucleus $(P V N)$, the increased release of adrenocorticotropin $(A C T H)$ into the blood stream by the pituitary gland, and the increased release of cortisol by the adrenal gland. Normally, cortisol exerts a negative feedback effect to shut down the stress response when the threat has passed. In depressed patients, the cortisol feedback mechanism is deficient due to the presence of glucocorticoid resistance, which may be caused either by polymorphisms of the corticosteroid receptor or by early (intra-uterine or childhood) developmental disorders. Both, increased $\mathrm{CRH}$ and increased cortisol levels may induce mood disorders by their central effects. The increased cortisol levels also affect the vasopressin (AVP) neurons in the suprachiasmatic nucleus (SCN) as they subsequently fail to inhibit sufficiently the CRH neurons in the hypothalamic paraventricular nucleus (PVN). Such an impaired negative feedback mechanism may lead to a further increase in the activity of the HPA system [13] 
High cortisol levels in depression may result in an impaired dopamine system [22], resulting in anhedonia (insensitiveness to pleasure or incapacity for experiencing happiness). Additionally, decreased levels of serotonin in the brain are thought to be of importance in anxiety disorders [23], panic disorders [24], and mood disorders, although this latter relation is most probably reflecting a vulnerability to suffer from depressive disorders [25].

Furthermore, sex hormone levels and particularly fluctuations in sex hormone levels may play an important role in the vulnerability to mood disorders [13]. Finally, the suprachiasmatic nucleus, i.e. the biological clock, which regulates circadian and circannual variations in neuronal, hormonal, and behavioral activity, is also involved. It is supposed to be related to circadian and circannual fluctuations in mood and to sleeping disturbances in depression and to hyperactivity of the HPA-axis [13].

\section{Genetic variants}

The genetic liability of a common familial disorder like major depression involves multiple genes. Potentially important genes have emerged that are related to the HPA axis, e.g., those that affect AVP, CRH, or cortisol synthesis as well as the production of their respective receptors. Another frequently studied gene is catechol-o-methyltransferase (COMT) that is related to the monoamine catabolism. Many other candidate genes have been proposed and investigated.

To date, the genetic underpinning of depression has been basically studied in three ways. First, linkage studies of informative families have been conducted to identify chromosomal regions (loci) likely to contain genes that contribute to susceptibility of depression. For example, several genome-wide linkage studies have identified regions of chromosomes 15q [26-28], 17p, and 8p [27] to be related to depression. Second, candidate gene association studies have focused on functional polymorphisms (DNA sequence variations that alter the expression and/or functioning of the gene product) in previously identified and new loci encoding for potentially relevant genes, as exemplified above. Many findings of this candidate gene approach can be considered promising but not definitive. The multiple genes involved in depression each exerts a small effect, making genetic linkage and association studies challenging [29]. Some consistent patterns have only recently emerged. For example, the following five genes were significantly associated with major depressive disorder in meta-analyses of polymorphisms that had been investigated in at least three studies [30]: apolipoprotein E (APOE), guanine nucleotide-binding protein (GNB3), methylenetetrahydrofolate reductase (MTHFR), dopamine transporter (SLC6A3), and serotonin transporter (SLC6A4).
Third, genome-wide association studies examine many polymorphisms simultaneously in large samples of unrelated, population-based cases (those with depression) and controls (those without depression). The first genome-wide association study of depression examined more than 430,000 single nucleotide polymorphisms (SNPs) in 1,738 cases of major depression and 1,802 controls and suggested preliminary evidence for the involvement of the presynaptic protein piccolo (PCLO) on chromosome 7 [31]. The results from multiple replication cohorts $(6,079$ independent cases with major depressive disorder and 5,893 controls) remained inconclusive. However, reanalysis of the PCLO replication study indicated that there was convincing evidence for the potentially causal association of major depressive disorder with one particular SNP, rs2522833, in PCLO [32]. Interestingly, the second genome-wide association study based on two large, independent data sets and a further combined analysis using a meta-analytical approach [33] failed to identify any SNP that achieved significance. The authors concluded that SNPs with substantial odds ratio are unlikely to exist for major depression disorder, at least among the studied SNPs to date.

A consistent, negative finding is worth mentioning. According to the monoamine-deficiency hypothesis, deficits in serotonin were thought to play a predominant role in the pathophysiology of depression [34]. However, antidepressant drugs made to replenish the lack of these neurotransmitters, like serotonin reuptake inhibitors (SSRIs), were shown not to be effective in large groups of patients suffering from depression [22]. In addition, there is no simple relationship between serotonin levels in the brain and mood [25]. Moreover, the fact that SSRIs take weeks to become effective makes also clear that the serotoninergic system cannot play a primary role in mood disorders. Finally, a recent meta-analysis was conducted of the interaction between the serotonin transporter gene (5-HTTLPR) and stressful life events on depression using a total sample of 14,250 participants divided into cases and controls. This study did not yield evidence that this serotonin transporter gene alone or in interaction with stressful life events is associated with an elevated risk of depression [35].

\section{Positive emotional states}

\section{Causes of individual differences}

An increasing number of twin studies showed substantial heritability of positive emotional states, such as subjective well-being and life satisfaction. Heritability estimates ranged between 40 and $50 \%$, whereas the remaining 
variance was accounted for by environmental influences unique to an individual. No effects of environmental influences shared by members of the same family were found [36-44]. Bartels and Boomsma [45] examined the etiology of different operationalizations of positive emotional states: quality of life in general, satisfaction with life, quality of life at present, and subjective happiness. Multivariate analyses with over 5,000 genetically related individuals revealed that the four measures all loaded on similar sets of genes. Genetic factors specific to the four measures were negligible.

A recent study by Boardman et al. [46] addressing the heritability of resilience merits attention because of its operationalization. Resilience was measured by a six-item positive emotional measure ("During the past 30 days, how much of the time did you feel ... cheerful? in good spirits?" etc.). They used the residual variance of this positive emotional measure, after adjusting for an exhaustive list of social and interpersonal stressors. In a sample of 527 twin pairs, aged 25-74, the heritability of resilience for men was found to be $52 \%$ and for women $38 \%$. Thus, the residual variance of positive affect or resilience was also found to be heritable, albeit more for men than for women.

Personality characteristics such as optimism, selfesteem, autonomy, mastery, personal growth, and selfacceptance play important roles in mental health status and subjective well-being [46-49]. For example, optimism as defined in terms of positive generalized outcome expectancies [50] may serve as a protective buffer against mental as well as physical health impairments. Optimism has been found to enhance, for example, adjustment to heart disease [51] and cancer [52] (for a brief review of such studies, see 49).

Recent twin studies indicate that these traits are not only associated within individuals, but also tend to share common genetic factors with positive emotional states. For example, multivariate genetic modeling of data derived from 428 twin pairs, aged 23-24, indicated that genes influencing optimism (measured with the Life Orientation Test), self-esteem (measured with the Rosenberg scale), and life satisfaction are largely overlapping [48]. The largest study to date, using 3,053 twin individuals over 50 years, also found that the same set of genes was found to be involved in optimism (also measured with the revised Life Orientation Test), overall health (measured by a single item: "how would you describe your health at present"), and mental health (measured with the General Health Questionnaire, GHQ-12) [49]. Thus, these factors share a genetic core that might represent the heritable mechanism behind an individual's positive orientation [48]. Nevertheless, a substantial amount of the variance in these traits is still explained by non-shared, specific environmental effects.
Biological pathways and genetic variants

Several studies suggest that the prefrontal cortex is a candidate brain area for happiness and positive emotional states that may be related to taste [53], smell [54] or other inputs via the somatosensory system [55]. Some electroencephalographic (EEG) studies suggest that positive emotional states are associated with increased left cortical power in the alpha frequency compared to the right hemisphere $[56,57]$. There is also evidence that dopamine modulates positive emotional states [58], indicating a role for the ventral tegmental area. At the subcortical level, a number of neuropeptide systems have been implicated in positive emotional states, e.g., neurotensin and cocaineand amphetamine-regulated transcript (CART) (both closely associated with dopamine), neuropeptide $\mathrm{Y}$, and oxytocin [58]. Finally, reduced activity of the neuroendocrine [59-61] and cardiovascular systems [58], as well as increased activity of the immune system [58], may all be involved in positive emotional states. However, genes or genomic regions of interest for positive emotional states have not been published at the time of paper writing.

\section{Discussion}

We have described the major results of the studies addressing the heritability of and biological pathways and genetic variants involved in negative and positive emotional states, respectively. These affect states are to a substantial degree heritable, with positive states being slightly more heritable (40-50\%) than negative states (30-40\%). The remaining variances can be attributed to environmental influences unique to the individual, in which the intrauterine period may play an important role. Perhaps contrary to some people's expectation, emotional states are not affected by environmental influences shared by family members. Another finding is that these mood states share common genetic factors with related personality traits, such as neuroticism for negative emotional states and optimism and self-esteem for positive emotional states. An abundance of studies have focused on the delineation of the biological pathways of negative affect, with the HPA axis considered as the 'final common pathway' of depressive symptoms. By contrast, biological and genetic research into positive emotional states is scarce. Multiple genes are involved in emotional states, each exerting a small effect. While the rate of progress is dazzling, particularly for negative affect, the biological complexities do not allow definitive answers yet.

A note of caution is warranted. The studies reviewed employed very different samples, study designs, measures, and analyses thereby potentially limiting their comparability. 
Particularly, the highly divergent self-report measures across studies merit attention as reviews and meta-analyses generally ignore these different sources. The question arises whether such collapsing of data is warranted. The cited study by Bartels and Boomsma [45] examining the etiology of four different operationalizations of positive affect is enlightening. They found that the four measures were explained by one underlying genetic factor and genetic factors specific to the four measures were negligible. The implication of this finding is that distinct measures of subjective well-being are not distinct at the genetic level and represent biological overlapping constructs. Thus, different studies that collect distinct measures of positive emotional states can be compared. Moreover, pooling data across measures is acceptable, at least for these four measures of positive emotional state. Whereas this finding is heartening, further research is needed to examine the extent to which different measures assessing similar emotional states, or QL domains, also share a similar genetic factor.

An intriguing and pressing question is the extent to which negative and positive emotional states share the same biological and genetic substrate. There is evidence of some common biological mechanism. For example, the dopamine system is involved in negative as well as positive affect. However, the relatively recent finding that high levels of distress can co-occur with high levels of wellbeing plead for, at least partly, independent biological mechanisms. Clearly, further studies are needed to disentangle the biological and genetic substrates of negative and positive affect, using data sets that include information on both phenotypes.

To avoid a possible misunderstanding about the implications of heritability studies, we would like to call attention to the fact that a high level of heritability does not mean that environmental influences are unimportant. Genes only influence phenotypes within an environment [46]. For example, experimental manipulations of loneliness were found to have powerful effects on mood, shyness, anxiety, and self-esteem [in 18]. Moreover, interventions based on simple and popular concepts such as committing acts of kindness, expressing gratitude or forgiveness, and thoughtful self-reflection had the power to induce a sustainable increase in levels of happiness [62].

At this point, QL researchers may wonder why we need to know the genes if we can examine the presence and severity of depression, extent, and level of happiness, as well as the related personality characteristics by self-report? Molecular genetic studies may provide insights into a wide variety of complex questions that traditional QL studies cannot deliver. For example, how can we identify patients who are vulnerable to long-lasting distress following a diagnosis? How can we predict which patients will suffer from mood disturbances when taking a specific chemotherapeutic regimen? Why do some pharmacotherapeutic treatments not work in all patients with the 'same' level of distress? Which patients would benefit from simple interventions to sustainably increase happiness? Why are some psychotherapies not effective in comparable patients with the same 'problem'? Why do supportive interventions, which one would expect to benefit all patients, often help only a few? Delineation of biological pathways through which various genetic predispositions propel people toward negative or away from positive emotions is needed. Moreover, insight into which patients will respond to which interventions can only be provided by studies assessing the patients' relative risk for negative and likelihood of positive emotions using family and molecular genetic approaches in combination with assessments of the risk and protective environmental factors. This insight in turn will help us to design more effective supportive programs that could moderate the outcomes of genetically based predispositions.

For example, if we can identify which patients are genetically predisposed to experience intense negative or extreme positive affect, preventive measures such as selfhelp programs or cognitive behavioral therapy can be implemented. Further, if the patient is entering into a phase of life where unavoidable stressors are present, such as a diagnosis of a chronic disease, supportive care interventions targeted at negative and positive affect or pharmacotherapy can be used concurrently with other treatments that can ultimately lead to better treatment outcomes, including survival. The individual, genetic profile would thus help indicating which treatment or support would be most helpful for a particular patient.

In sum, the combination of the prognostic value of genetic, environmental risk and protective factors ultimately enables appropriate and effective support [63]. Clearly, molecular genetic testing is a long way from being implemented in clinical settings, and to some, the previously sketched vision might seem science fiction. However, to realize this vision, we believe that QL research should embrace the study of the genetic and environmental influences of both negative and positive affects as the resulting insight will ultimately help our patients to become not only happier but also healthier.

Acknowledgments We are indebted to Carolyn Schwartz and Jeff Sloan for helpful comments to earlier drafts of this article.

Open Access This article is distributed under the terms of the Creative Commons Attribution Noncommercial License which permits any noncommercial use, distribution, and reproduction in any medium, provided the original author(s) and source are credited. 
Appendix: glossary [cited from 64]

Chromosome: Structure that is composed mainly of chromatin, which contains DNA and resides in the nucleus of cells.

DNA (deoxyribonucleic acid): The-stranded molecule that encodes genetic information.

Family study: Assessing the resemblance between genetically related parents and offspring and between siblings living together. Resemblance can be due to heredity or to shared family environment.

Gene: The basic unit of inheritance. A sequence of DNA bases that codes for a particular product.

Genome: All the DNA sequences of an organism.

Genotype: The genetic constitution of an individual.

Heritability: The proportion of the phenotypic differences that can be attributed to genetic differences in a particular population.

Linkage: Close proximity of loci on a chromosome.

Linkage analysis: A technique that detects linkage between DNA markers and traits used to map genes to chromosomes.

Locus (plural, loci): The site of a specific gene on a chromosome.

Mapping: Linkage of DNA markers to a chromosome and to specific regions of chromosomes.

Nucleus: The part of the cell that contains chromosomes.

Phenotype: An observed characteristic of an individual that results from the combined effects of genotype and environment.

Polymorphism: A locus with two or more alleles (alternative forms of a gene at a locus). (Functional polymorphism: DNA sequence variations that alter the expression and/or functioning of the gene product)

Single nucleotide polymorphism (SNP): Sequences in the genome that differ by a single nucleotide between one portion of the population and another.

Twin study: Comparing the resemblance of identical and fraternal twins to estimate genetic and environmental components of variance.

\section{GENEQOL Consortium participants per March 2009}

Amy P. Abertnethy, Duke Cancer Care Research Program, Duke University Medical Center, Durham, NC, US; Frank Baas, Laboratory of Neurogenetics, Academic Medical Center, University of Amsterdam, Amsterdam, The Netherlands; Andrea M. Barsevick, Nursing Research and
Education, Fox Chase Cancer Center, Philadelphia, PA, US; Meike Bartels, Department of Biological Psychology, VU University, Amsterdam, the Netherlands; Dorret I. Boomsma, Department of Biological Psychology, VU University, Amsterdam, the Netherlands; Cynthia Chauhan, Cancer Advocay, Wichita, KS, US; Charles S. Cleeland, Department of Symptom Research, The University of Texas M. D. Anderson Cancer Center, Houston, TX, US; Amylou C. Dueck, Section of Biostatistics, Mayo Clinic, Scottsdale, AZ, US; Marlene H. Frost, Women's Cancer Program, Mayo Clinic, Rochester, MN, US; Per Hall, Department of Medical Epidemiology and Biostatistics, Karolinska Institute, Stockholm, Sweden; Michele Y. Halyard, Department of Radiation Oncology, Mayo Clinic, Scottsdale, AZ, US; Pål Klepstad, Department of Intensive Care Medicine, St Olavs University Hospital, Norwegian University of Technology and Science, Trondheim, Norway; Nicholas G. Martin, Queensland Institute of Medical Research, Brisbane, Australia; Christine Miaskowski, School of Nursing, University of California, San Francisco, CA, US; Miriam Mosing, Queensland Institute of Medical Research, Brisbane, Australia; Benjamin Movsas, Department of Radiation Oncology, Henry Ford Health System, Detroit, MI, US; Cornelis J. F. Van Noorden, Department of Cell Biology and Histology, Academic Medical Center, University of Amsterdam, Amsterdam, The Netherlands; Donald L. Patrick, Department of Health Services, University of Washington, Seattle, WA, US; Nancy L. Pedersen, Department of Medical Epidemiology and Biostatistics, Karolinska; Institute, Stockholm, Sweden; Mary E. Ropka, Cancer Prevention and Control Program, Fox Chase Cancer Center, Cheltenham, PA, US; Quiling Shi, Department of Symptom Research, The University of Texas M. D. Anderson Cancer Center, Houston, TX, US; Gen Shinozaki, Department of Psychiatry and Psychology, Mayo Clinic, Rochester, MN, US; Jasvinder A. Singh, Minneapolis Veterans Affairs Medical Center and University of Minnesota, Minneapolis, MN and Mayo Clinic College of Medicine, Rochester, MN, US; Jeff A. Sloan, Department of Health Sciences Research, Mayo Clinic, Rochester, MN, US; Mirjam A. G. Sprangers, Department of Medical Psychology, Academic Medical Center, University of Amsterdam, Amsterdam, The Netherlands; Ruut Veenhoven, Faculty of Social Sciences, Erasmus University Rotterdam, Rotterdam, The Netherlands; Ping Yang, Department of Genetic Epidemiology, Mayo Clinic, Rochester, MN, US; Ailko H. Zwinderman, Department of Clinical Epidemiology and Biostatistics, Academic Medical Center, University of Amsterdam, Amsterdam, The Netherlands. 


\section{References}

1. Aaronson, N. K., Ahmedzai, S., Bergman, B., Bullinger, M., Cull, A., Duez, N. J., et al. (1993). The European Organization for Research and Treatment of Cancer Study Group on Quality of Life: The EORTC QLQ-C30: A quality of life instrument for use in international clinical trials in oncology. Journal of the National Cancer Institute, 85, 365-367.

2. Folkman, S. (2008). The case for positive emotions in the stress process. Anxiety, Stress, \& Coping, 21, 3-14.

3. Folkman, S. (1997). Positive psychological states and coping with severe stress. Social Science Medicine, 45, 1207-1221.

4. Fredrickson, B. L. (1998). What good are positive emotions? Review of General Psychology, 2, 300-319.

5. Pressman, S. D., \& Cohen, S. (2005). Does positive emotional influence health? Psychological Bulletin, 131, 925-971.

6. Howell, R. T., Kern, M. L., \& Lyubomirsky, S. (2007). Health benefits: Meta-analytically determining the impact of well-being on objective health outcomes. Health Psychology Reviews, 1, 83-136.

7. De Gargino, J. P. (2004). Children's health and the environment: A global perspective. Geneva: World Health Organization.

8. Fowler, J. H., \& Christakis, N. A. (2008). Dynamic spread of happiness in a large social network: Longitudinal analysis over 20 years in the Framingham Heart Study. British Medical Journal, 337, a2338. doi:10.1136/bmj.a2338.

9. Wilson, I. B., \& Cleary, P. D. (1995). Linking Clinical Variables with health-related quality of life. A conceptual model of patient outcomes. Journal of the American Medical Association, 273, 59-65.

10. Sprangers, M. A. G., Sloan, J., Barsevick, A., Chauhan, C., Dueck, A. C., Raat, H., Shi, Q., \& the GENEQOL Consortium. Scientific imperatives, clinical implications, and theoretical underpinnings for the investigation of the relationship between genetic variables and patient-reported quality-of-life outcomes. Quality of Life Research, manuscript under review.

11. Sullivan, P. F., Neale, M. C., \& Kendler, K. S. (2000). Genetic epidemiology of major depression: Review and meta-analysis. American Journal of Psychiatry, 157, 1552-1562.

12. Hettema, J. M., Neale, M. C., \& Kendler, K. S. (2001). A review and meta-analysis of the genetic epidemiology of anxiety disorders. American Journal of Psychiatry, 158, 1568-1578.

13. Bao, A., Meynen, G., \& Swaab, D. F. (2008). The stress system in depression and neurodegeneration: Focus on the human hypothalamus. Brain Research Reviews, 57, 531-553.

14. Middeldorp, C. M., Cath, D. C., Van Dyck, R., \& Boomsma, D. I. (2005). The co-morbidity of anxiety and depression in the perspective of genetic epidemiology. A review of twin and family studies. Psychological Medicine, 35, 611-624.

15. Levinson, D. F. (2006). The genetics of depression: A review. Biological Psychiatry, 60, 84-92.

16. Rettew, D. C., Vink, J. M., Willemsen, G., Doyle, A., Hudziak, J. J., \& Boomsma, D. I. (2006). The genetic architecture of neuroticism in 3301 Dutch adolescent twins as a function of age and sex: A study from the Dutch Twin Register. Twin Research and Human Genetics, 9(1), 24-29.

17. Wray, N. R., Birley, A. J., Sullivan, P. F., Visscher, P. M., \& Martin, N. G. (2007). Genetic and phenotypic stability of measures of neuroticism over 22 years. Twin Research and Human Genetics, 10(5), 695-702.

18. Boomsma, D. I., Cacioppo, J. T., Muthén, B., Asparouhov, T., \& Clark, S. (2007). Longitudinal genetic analysis for loneliness in Dutch twins. Twin Research and Human Genetics, 10(1), 267-273.

19. Boomsma, D. I., Willemse, G., Dolan, C. V., Hawkley, L. C., \& Cacioppo, J. T. (2005). Genetic and environmental contributions to loneliness in adults: The Netherlands twin register study. Behavioral Genetics, 35, 745-752.

20. Bartels, M., Cacioppo, J. T., Hudziak, J. J., \& Boomsma, D. I. (2008). Genetic and environmental contributions to stability in loneliness throughout childhood. American Journal of Medical Genetics Part B, 147B, 385-391.

21. Bartels, M., van den Berg, M., Sluyter, F., Boomsma, D. I., \& de Geus, E. J. C. (2003). Heritability of cortisol levels: Review and simultaneous analysis of twin studies. Psychoneuroendocrinology, 28, 121-137.

22. Dunlop, B. W., \& Nemeroff, C. B. (2007). The role of dopamine in the pathophysiology of depression. Archives of General Psychiatry, 64, 327-337.

23. Lesch, K. P., Zeng, Y., Reif, A., \& Gutknecht, L. (2003). Anxiety-related traits in mice with modified genes of the serotonergic pathway. European Journal of Pharmacology, 480, 185-204.

24. Maron, E., \& Shlik, J. (2006). Serotonin function in panic Disorder: Important, but why? Neuropharmacology, 31, 1-11.

25. Ruhe, H. G., Mason, N. S., \& Schene, A. H. (2007). Mood is indirectly related to serotonin, norepinephrine and dopamine levels in humans: A meta-analysis of monoamine depletion studies. Molecular Psychiatry, 12, 331-359.

26. Holmans, P., Zubenko, G. S., Crowe, R. R., DePaulo, J. R., Scheftner, W. A., Weissman, M. M., et al. (2004). Genomewide significant linkage to recurrent, early-onset major depressive disorder on chromosome 15q. The American Journal of Human Genetics, 74(6), 1154-1167.

27. Holmans, P., Weissman, M. M., Zubenko, G. S., Scheftner, W. A., Crowe, R. R., DePaulo, J. R., et al. (2007). Genetics of recurrent early-onset major depression (GenRED): Final genome scan report. American Journal of Psychiatry, 164(2), 248-258.

28. McGuffin, P., Knight, J., Breen, G., Brewster, S., Boyd, P. R., Craddock, N., et al. (2005). Whole genome linkage scan of recurrent depressive disorder from the depression network study. Human Molecular Genetics, 14(22), 3337-3345.

29. McGuffin, P., Cohen, S., \& Knight, J. (2007). Homing in on depression genes. American Journal of Psychiatry, 164(2), 195-197.

30. López-León, S., Janssens, A. C. J. W., Ladd, A. M. G.-Z., Del-Favero, J., Claes, S. J., Oostra, B. A., et al. (2008). Metaanalyses of genetic studies on major depressive disorder. Molecular Psychiatry, 13, 772-785.

31. Sullivan, P. F., De Geus, E. J. C., Willemsen, G., James, M. R., Smit, J. H., Zandbelt, T., et al. (2009). Genome-wide association for major depressive disorder: A possible role for the presynaptic protein piccolo. Molecular Psychiatry, 14(4), 359-375.

32. Bochdanovits, Z., Verhage, M., Smit, A. B., de Geus, E. J. C., Posthuma, D., Boomsma, D. I., et al. (2009). Joint reanalysis of 29 correlated SNPs supports the role of PCLO/Piccolo as a causal risk factor for major depressive disorder. Molecular Psychiatry, $14,650-652$.

33. Muglia, P., Tozzi, F., Galwey, N. W., Francks. C., Upmanyu, R., Kong, X. Q., et al. (2008). Genome-wide association study of recurrent major depressive disorder in two European case-control cohorts. Molecular Psychiatry, December 23, epub ahead of print.

34. Belmaker, R. H., \& Agam, G. (2008). Major depressive disorder. New England Journal of Medicine, 358, 55-68.

35. Risch, N., Herrell, R., Lehner, T., Liang, K. Y., Eaves, L., Hoh, J., et al. (2009). Interaction between the serotonin transporter gene (5HTTLPR), stressful life events, and risk of depression a metaanalysis. JAMA, 301(23), 2462-2471.

36. Bergeman, C. S., Plomin, R., Pedersen, N. L., \& McClearn, G. E. (1991). Genetic mediation of the relationship between social support and psychological well-being. Psychology Aging, 6, 640-646. 
37. Harris, J. P., Pedersen, N. L., Stacey, C., McClearn, G. E., \& Nesselroade, J. R. (1992). Age differences in the etiology of the relationship between life satisfaction and self-rated health. Journal of Aging and Health, 4, 349-368.

38. Lykken, D. T., \& Tellegen, A. (1996). Happiness is a stochastic phenomenon. Psychological Science, 7, 186-189.

39. Newman, D. L., Tellegen, A., \& Bouchard, T. J., Jr. (1998). Individual differences in adult ego development: Sources of influence in twins reared apart. Journal of Personality and Social Psychology, 74(4), 985-995.

40. Roysamb, E., Harris, J., Mangus, P., Vitterso, J., \& Tambs, K. (2002). Subjective well being. Sex specific effects of genetic and environmental factors. Personality and Individual Differences, $32,211-223$.

41. Roysamb, E., Tambs, K., Reichborn-Kjennerud, T., Neale, M. C., \& Harris, J. R. (2003). Happiness and health: Environmental and genetic contributions to the relationship between subjective wellbeing, perceived health, and somatic illness. Journal of Personality and Social Psychology, 85(6), 1136-1146.

42. Stubbe, J. H., Posthuma, D., Boomsma, D. I., \& De Geus, E. J. (2005). Heritability of life satisfaction in adults: A twin-family study. Psychological Medicine, 35(11), 1581-1588.

43. Tellegen, A., Lykken, D. T., Bouchard, T. J., Wilcox, K. J., Rich, S., \& Segal, N. L. (1988). Personality similarity in twins reared apart and together. Journal of Personality and Social Psychology, 54, 1031-1039.

44. Nes, R. B., Røysamb, E., Tambs, K., Harris, J. R., \& ReichbornKjennerud, T. (2006). Subjective well-being: Genetic and environmental contributions to stability and change. Psychological Medicine, 36, 1033-1042.

45. Bartels, M., \& Boomsma, D. I. Born to be happy? (2009). The etiology of subjective wellbeing. Behavior Genetics, doi: 10.1007/s10519-009-9294-8.

46. Boardman, J. D., Blalock, C. L., \& Button, T. M. M. (2008). Sex differences in the heritability of resilience. Twin Research and Human Genetics, 11, 12-27.

47. Kessler, R. C., Gilman, S. E., Thornton, L. M., \& Kendler, K. S. (2004). Health, well-being, and social responsibility in the MIDUS twin and sibling subsamples. In O. G. Brim, C. D. Ryff, \& R. C. Kessler (Eds.), How healthy are we?: A national study of well-being at midlife (pp. 124-152). Chicago: University of Chicago Press.

48. Caprara, G. V., Fagnani, C., Alessandri, G., Steca, P., Gigantesco, A., Sforza, L. L. C., et al. (2009). Human optimal functioning: The genetics of positive orientation towards self, life, and the future. Behavioral Genetics, 39, 277-284.

49. Mosing, M. A., Zietsch, B. P., Shekar, S. N., Wright, M. J., Martin, N. G. (2009). Genetic and environmental influences on optimism and its relationship to mental and self-rated health: A study of aging twins. Behavioral Genetics, published online 18 July. doi:10.1007/s10519-009-9287-7.
50. Scheier, M. F., \& Carver, C. S. (1985). Optimism, coping, and health-assessment and implications of generalized outcome expectancies. Health Psychology, 4(3), 219-247.

51. Matthews, K. A., Raikkonen, K., Sutton-Tyrrell, K., \& Kuller, L. H. (2004). Optimistic attitudes protect against progression of carotid atherosclerosis and healthy middle-aged women. Psychosomatic Medicine, 66(5), 640-644.

52. Trunzo, J. J., \& Pinto, B. M. (2003). Social support as a mediator of optimism and distress in breast cancer survivors. Journal of Consulting Clinical Psychology, 71(4), 805-811.

53. Kringelbach, M. L., O’Doherty, J., Rolls, E. T., \& Andrews, C. (2003). Activation of the human orbitofrontal cortex to a liquid food stimulus is correlated with its subjective pleasantness. Cerebral Cortex, 13, 1064-1071.

54. Rolls, E. T., Kringelbach, M. L., \& de Araujo, I. E. (2003). Different representations of pleasant and unpleasant odours in the human brain. European Journal of Neuroscience, 18, 695-703.

55. Rolls, E. T., O'Doherty, J., Kringelbach, M. L., Francis, S., Bowtell, R., \& McGlone, F. (2003). Representations of pleasant and painful touch in the human orbitofrontal and cingulate cortices. Cerebral Cortex, 13, 308-317.

56. Davidson, R. J. (2004). What does the prefrontal cortex 'do' in emotional: Perspectives on frontal EEG asymmetry research. Biological Psychology, 67, 219-233.

57. Tomarken, A. J., Davidson, R. J., Wheeler, R. E., \& Doss, R. C. (1992). Individual differences in anterior brain asymmetry and fundamental dimensions of emotion. Journal of Personality and Social Psychology, 62, 676-687.

58. Burgdorf, J., \& Panksepp, J. (2006). The neurobiology of positive emotions. Neuroscience Biobehavioral Review, 30(2), 173-187.

59. Steptoe, A., \& Wardle, J. (2005). Positive affect and biological function in everyday life. Neurobiology of Aging, 26, 108-112.

60. Steptoe, A., Wardle, J., \& Marmot, M. (2005). Positive affect and health-related neuroendocrine, cardiovascular, and inflammatory processes. Proceedings of the National Academy of Sciences USA, 102, 6508-6512.

61. Steptoe, A., O’Donnell, K., Badrick, E., Kumari, M., \& Marmot, M. (2008). Neuroendocrine and inflammatory factors associated with positive affect in healthy men and women: The Whitehall II study. American Journal of Epidemiology, 167, 96-102.

62. Lyubomirsky, S., Sheldon, K. M., \& Schkade, D. A. (2005). Pursuing happiness: The architecture of sustainable change. Review of General Psychology, 9, 111-131.

63. Bartels, M., \& Hudziak, J. J. (2007). Genetically informative designs in the study of resilience in developmental psychopathology. Child Adolescents Psychiatric Clinical North America, 16, 323-339.

64. Plomin, R., DeFries, J. C., McClearn, G. E., \& McGuffin, P. (2001). Behavioral genetics (4th ed., pp. 1-449). New York: Worth Publishers and W. H. Freeman and Company. 